Received: January 18, 2021 / Accepted: March 27, 2021 / Published online: July 2, 2021

The $($ C Author(s) 2021. This article is published with open access at Academia Analitica

ORIGINAL SCIENTIFIC PAPER

UDC: 1 Davidson, D.

\title{
Against Epistemological Virus of Scepticism: Davidson on Objectivity of Knowledge
}

\author{
Kenan Šljivo ${ }^{1}$
}

\begin{abstract}
This paper provides a short overview of approaches to epistemological issues as represented by Donald Davidson, an American philosopher. This is an attempt to analyse Davidson's essential postulates, in order to construct a framework for understanding a highly authentic epistemological position and the way in which it appears as an antipode to the sceptical epistemological strategies. In other words the goal is to identify a coordinate system, through a set of postulates, from which Davidson projects his epistemological attitudes. For that purpose, the paper presents the developmental process of Davidson's epistemological thought that goes through triangulation of notions subjective, intersubjective, and objective. The paper places special emphasis on Davidson's concentration on communicative practices and intersubjectivity as the only topoi in which the issue of objectivity can be raised.
\end{abstract}

Key words : Donald Davidson, knowledge, scepticism, externalism, subjectivity, intersubjectivity, objectivity

\footnotetext{
${ }_{1}$ K.Šljivo

University of Sarajevo, Faculty of Philosophy, Dept. of Philosophy

Franje Rackog 1, 71.000 Sarajevo, Bosnia and Herzegovina

kenosljivo@hotmail.com
} 


\section{Introduction}

Donald Davidson, an American philosopher, presented his viewpoints in numerous essays and their thematic diversity disables an "immediate insight" into a philosophical system that would connect them into a whole. Davidson treated numerous themes: the truth - meaning relationship, interpretation, translation, knowledge, beliefs, rationality, free will, etc. However, many researchers of his philosophy (Kirk Ludwig, Ernie Lapore, Simon Evnine, Barry Stroud, Thomas Nagel, etc.) have shown that Davidson's essential doctrinal and conceptual presuppositions are coherently and consistently exposed to all these diverse themes. Regardless of different purposes of research and approaches, there exists almost a uniform standpoint regarding one goal of his philosophy: they have all clearly identified that Davidson's thematisation of epistemological issues is aimed at the mainstay and objectivity of knowledge.

Researchers agree that Davidson, in his texts contained in collections of essays (Essays on Action and Events; Subjective, Intersubjective, Objective; Problems of Rationality; Inquiries into Truth and Interpretation), was researching a wide spectrum of knowledge and problems that concern classical issues of certainty, the structure and domain of knowledge, with a determined goal (one of many): he wanted to show that sceptical positions on the nature of knowledge are unsustainable and, accordingly, to justify the viewpoint that the objective is possible. This paper aims to research and analytically examine the importance of Davidson's theses and to accentuate the spectrum of possible consequences that arise from them. For that purpose, we will follow theinstigation of Davidson's position through the way in which he articulates the notions of subjectivity, intersubjectivity, and objectivity.

\section{The Dogmas of Scepticism}

Issues of certainty and universality of knowledge are classical epistemological issues. Classical epistemology was conceived and developed in segments of modernist philosophies, and its central task was to ensure that knowledge is founded universally and that the foundation is clear and distinct. In this regard, scepticism may be determined as an epistemological position: that is, every teaching that negatively determines the tendency of theories of cognition, which go towards an absolute certainty and universality, and a teaching which strategically aims to show the implausibility of theoretical patterns bearing such demands. The initial idea of Davidson's approach to epistemological issues is related to his questioning of 
plausibility of the theoretical patterns that enable the appearance and development of a sceptical viewpoint. Stroud analysed Davidson's positions and presented a thesis that Davidson's teaching is in the widest cense Kantian, for it aims to show the ineffectiveness of scepticism.

"There is a very general philosophical question which asks how, on the basis of what human beings get through the senses, they can ever have good reason to accept the beliefs, hypotheses, and theories they hold about the world. What is in question are the credentials or the degree of wellfoundedness of what is taken to be a fully-formed conception of the world and our place in it, as embodied in everything we believe. To show how (or which of) those beliefs amount to knowledge, or to beliefs we have good reason to hold, would be to explain, philosophically, how knowledge of the world is possible. If there are no such reasons, or our best reasons are inadequate, scepticism is the right answer; we do not know what we think we know. Donald Davidson regards this philosophical question as misguided. He thinks that if we understood better how we could even be in a position to ask it, we would see that it can present no threat of general scepticism. In this respect, his approach is akin to that of Kant. Kant thought an understanding of the possibility of thought and experience in general was essential to, perhaps sufficient for, an understanding of the possibility of knowledge. This idea too is present in Davidson.” (Stroud, 1999: 139)

What is more interesting than Stroud's thesis is that he recognized Davidson's focus on a tendency enrooted in the very essence of classical epistemology: every theory of knowledge, in order to achieve any degree of validity, must consider sceptical arguments and the sceptical position in general. However, without an attempt to further discuss Stroud's position on Kantian motives behind Davidson's theory of knowledge, we find it justifiable to claim that Davidson recognizes the aforementioned theories (enabling sceptical arguments) in accordance with the principle that rests in their very essence: namely, the traditional separation of the conceptual scheme and its content is the principal methodological fallacy that paves the way to relativist and sceptical conceptions of knowledge.

Davidson does not accept this division and thinks it should be rejected, since it (the division) states that there is, epistemologically speaking, a privileged status of the phenomena that are postulated by such a division. We see that Davidson does not separate the epistemological themes from semantical issues. They are closely connected. Hence, understanding the meaning of linguistic universalities is in the essence of the epistemological issue of nature and structure of knowledge. When these postulates are observed this way, it appears that the entire semantic analysis conducted in Inquiries into Truth and Interpretation can be observed only as a blueprint for the epistemological aspect of Davidson's philosophy. Differentiating the conceptual scheme and content is a characteristic of philosophical strategies in the majority of philosophical systems. This distinction enables to understand 
language as a medium for shaping the sensory stimuli and to presuppose that they can always be shaped in a correct way in the conceptual scheme. Davidson emphasizes that, although there is a difference in their teaching on holism, on the value of differentiating the judgement to analytical and synthetic, etc., they share a basic presumption.

"But what concerns me here is that Quine and Dummett agree on a basic principle, which is that whatever there is to the meaning must be traced back somehow to experience, the given, or patterns of sensory stimulation, something intermediate between belief and the usual objects our beliefs are about. Once we take this step, we open the door to scepticism, for we must then allow that a very great many - perhaps most - of the sentences we hold to be true may in fact be false. It is ironical." (Davidson, 2001a: 144-145)

This paves the way towards, for epistemology, a more significant division: the division to what the subjective content of awareness and the real situation in the world independent of our awareness are. In the very analysis of this division, Thomas Nagel sees the authenticity of Davidson's rejection of scepticism and emphasises that it transgresses the borders of what he (Nagel) understands as part of the traditional methodologies of overcoming scepticism. According to Nagel, Davidson

"... does not reduce the objective to the subjective; and although in a sense it goes in the opposite direction, it does not proceed by reducing the subjective to something else that is objective, in the fashion of behaviorist philosophies of mind. It is not reductionist at all. Rather, Davidson insists on certain consequences of the fact that thought and subjective experience, the entire domain of appearances, must be regarded as elements of objective reality, and cannot be conceived apart from it. The subjective is in itself objective, and its connections with the objective world as a whole are such that the radical disjunction between appearance and reality that scepticism requires is not a genuine logical possibility." (Nagel, 1999, 196)

This is the new concept of Cogito. Nagel is right to claim that this concept is essentially Cartesian and that, however, this concept of Cogito is determined by another kind of facticity than the one observed in the Cartesian. Davidson too starts from the certainty of our own thoughts but does not believe that it is the form of knowledge different from other forms of knowledge. The question arises as to whether a reliable step out of our own self can be made, projecting its content into other spheres of reality. That is where the story about authority and autonomy of the subjective knowledge based on introspection, as well as on epistemology based on such knowledge, begins. 


\section{Externalism and the Limits of Subjectivity}

For the purpose of proving the impossibility of the thesis on epistemological primacy of the subjective content, Davidson mentions three kinds of knowledge that can be differentiated within the epistemological discourse: the knowledge on one's own mind, the knowledge on the external world, and the knowledge of the mind of others. In essence of this distinction is the conviction that we take a privileged approach to our own mind and its content. That is the topic that Davidson treats in numerous texts and, in our opinion, it is one of the most authentic contributions of his philosophy to epistemological issues. It would be necessary at this point to explain the foundations of such convictions. What is the difference between the knowledge in our own conscious content which is subsequently determined by the knowledge of the world around us, and the knowledge on the content of the mind of others? Some authors think that there is a special connection between ascribing the selfknowledge and responsibility that appears in the process (Bilgrami, 1999). In the sphere of the perceptive knowledge, this connection is especially prominent.

For Davidson, however, this is wrong. Rationalisation and justification of one's own beliefs is identical to the rationalisation and interpretation of all that is "beyond us". When we understand the self-knowledge on this principle, we are able to act responsibly when we interpret the other and the world around us.

"First person knowledge is distinguished by the fact that we can legitimately claim a unique sort of authority with respect to what we believe, want, intend, and some other attitudes. Second person knowledge and knowledge of the rest of the world of nature do not have this authority, but they differ from each other in that our knowledge of other minds is normative in a way the latter is not. All three varieties of knowledge are, however, objective in the sense that their truth is independent of their being believed to be true. This is obvious in the second two cases, but it holds even in the case of believes about our own beliefs and other attitudes: such beliefs can be wrong. All our knowledge is also objective in the sense that it could for the most part be expressed by concepts which have a place in a publically shared scheme of things." (Davidson, 2001a: xiii)

By this we are making a shift towards issues of hermeneutical practice that needs to rise above the aforementioned distinctions. Such a shift, according to Rorty, places Davidson in the ranks of the tradition that leaves the idea that there is a hidden human nature and some mental states that need to be expressed through language (Rorty, 1980).

The question arising now is: what is interpretation and what is its structure? Interpretation always starts from the principle of the one interpreting, the way that 
they project their own propositional-semantic coordinates into the area of "sense" of the one who interprets. In that process, we conduct various practical activities and procedures: we ascribe the meaning to sentences someone utters, we differentiate between the meaning of linguistic entities and knowledge on their meaning, we ascribe beliefs to the interlocutor through what they said, we identify intentions and representations of their speech acts, we estimate and legitimise different linguistic actions and behaviour, etc. That, however, does not mean that making a difference between beliefs about oneself, beliefs about other people, and beliefs about the world is justifiable. All these, conditionally speaking, kinds of knowledge are a part of the same corpus and they depend on interpretative strategies and capacities of the one who interprets.

For that purpose, Davidson develops the idea of radical interpretation that includes the charity principle, which that starts from an assumption that is authentically Davidsonian. That assumption stems from the fact that our conceptual scheme, the general image of the world shared by all people is not as different as Quine had thought. For Quine, this assumption on dependence of phenomenology from the culture in which individuals acquire language, and through the language also ontological and epistemological idioms that shape their image of the world, brought to light the idea of ontological and epistemological relativity and to claims on incommensurability of different cultural patterns. Davidson is aware that linguistic models vary, but that does not happen radically: it is because he observes the phenomenological matrixrealistically, which brings him to a conviction that cardinal differences in its linguistic shaping are not possible.

Davidson understands that the ontogenesis and psychogenesis of an individual are a topos of understanding of the nature of knowledge for naturalist epistemology, and that is a complex process that entails different biological and cultural matrices. However, the adoption of knowledge in a culture is always conducted through language and that is the only way it can be meaningfully described and characterised. This very continuity of adopting different content is what needs to be understood when one speaks of acquiring the notions and their linguistic articulation.

The second important matter isthat Davidson believesthat every explication of cognitive beliefs about the world around us, and which are expressed through a language with a structure and a meaning (syntax and semantics), needs to include a holistic aspect. Davidson explicitly rejects atomism, since it is not plausible when we think about the way in which human beings possess mental contents and 
express them in different linguistic universals. The belief and the linguistic form by which it is expressed do not exist isolated in our mind; they are always connected into a wholesome network of beliefs and meanings that, together with the reality of things, serve as conditions of their truthfulness and fallacy. Such contents are always coherent and it is difficult to imagine that they are false. In that way, the holism of belief and the holism of meaning are compatible. When Evnine calls Davidson's epistemological standpoint a rational idealism, he emphasises that his idealism is a consequence of understanding of meaning of linguistic universals only in the entirety of meaning.

"Davidson's idealism is a consequence of his semantic holism." (Evnine, 1991: 156) The central question that arises and that helps answer the question on objectivity of knowledge and truth is how the thought (belief) is possible at all (Davidson, 2004). Davidson here postulates the idea on objectivity of the content of thought. The objectivity of thought content normatively influences every interpreter. In order to be able to provide an answer to this question, we need to start from the fact that the beliefs that we recognise as primary may be wrong: recognising this fact shows that the truthfulness of belief is not an intrinsic subjective matter and that it always concerns an objective structure outside ourselves.

"To recognize the chance that we may be wrong is to recognize that beliefs can be tested - belief is personal, and in this sense subjective; truth is objective. The problem is to account for our having the concept of objectivity - of a truth that is independent of our will and our attitudes." (Davidson, 2004: 7)

Thus postulated methodological standpoint is classically externalist. The externalist thesis aims to show that things in our surroundings need to be considered in explaining our thoughts. "All externalist theories of thought content hold that some of our thoughts at least depend on our relations to our environments for their contents." (Lepore, Ludwig, 2005: 335)

For that purpose, we now need to shed light on and shortly examine Davidson's Omniscient Interpreter Argument, the purpose of which is to confirm the externalist thesis on the thought content. Davidson invites us to imagine someone with the complete knowledge of the world, apart from the knowledge that concerns attitudes of speakers and meanings of their sentences (Davidson, 2001a). It is clear that the omniscient interpreter should learn thesemeanings and their attitudes. Since the omniscient interpreter mainly has true beliefs on what surrounds him, Davidson proves that he would not be able to interpret only in case we almost fully disagree with him. That would entail that the image of the world that we have is radically 
different than his. However, we have seen that Davidson thinks that it is in human nature to mainly own true beliefs, and that they are in a coherent form.

"If the above argument is correct, any speaker must have a coherent set of beliefs which are largely true as a condition on being a speaker or having any beliefs at all. In this sense, we could say that any coherent set of beliefs is a largely true set of beliefs." (Lepore, Ludwig, 2005: 332)

We see that Davidson postulated here an interpretative matrix showing that communicative practices need to be recognised, understood and studied as a topos of articulation of thought: that is the only form in which human rational (and all other) capacities appear in a relevant form for the philosophical thought. That is why it makes sense to seek the answer to the question on objectivity of knowledge in relation with the linguistic and discursive practices. For that reason, in the following chapter, we will examine the possibility that is indicated in what has been previously said: we want to examine how is it possible to think a concept of knowledge intersubjectivity postulated as the root of its objectivity.

\section{Intersubjectivity as a Root of Objectivity}

We are of the opinion that the analysis has indicated guidelines of Davidson's thought. We will cite an excerpt from Sosa's study entitled "Knowledge of Self, Others, and World", which we believe summarises all that has previously been said in this paper. In the introduction of this excellent analysis of Davidson's epistemological position, Sosa (connecting Davidson and Kant, similar to Stroud) maintains that his philosophy contains in its core the elements of transcendentalism.

"Davidson's epistemology, like Kant's, features a transcendental argument as its centerpiece. Both philosophers reject any priority, whether epistemological or conceptual, of the subjective over the objective, attempting thus to solve the problem of the external world. For Davidson, three varieties of knowledge are coordinate - knowledge of the self, of other minds, and of the external world. None has priority." (Sosa, 2003: 163)

However, Davidson's transcendentalism (if one is able to accept that stance) is special. That is the transcendentalism that is closer to the tradition of a communicative community's transcendental apriorism, and, in that sense, it can be viewed as a continuum of this tradition, but in its specifically pragmatic-holistic attire. Davidson rejects every idea of a subjectively-oriented epistemic essentialism and seeks answers in the spheres of social ability of communication/understanding in the classical pragmatic manner. The consequence of such thinking is a shift 
towards an intersubjective/communicative practice of exchange of thoughts expressed through sentences as their linguistic forms. Here we want to emphasise that Davidson's use of the term 'intersubjective' means that which is acceptable to different atomised subjects. In that context, an intersubjectively acceptable fact is almost always synonymous with that which is objective in epistemological sense. We can say that the terms intersubjectivity and objectivity are almost analytical reduplications and that they can most frequently change in different sentence patterns. In other words, epistemology focused on a strong subject, isolatedfrom social structures and processes, should be abandoned, which enables to formulate a new position: intersubjectivity is the only framework for research and understanding knowledge objectivity. We think this is what Habermas had in mind when he stated the following, in an attempt to differentiate between representation and understanding:

"In contrast to representation or cognition, coming to understanding requires the rider uncoerced, because the expression is meant to be used here as a normative concept. From the perspective of the participants, coming to an understanding is not an empirical event that causes de facto agreement; it is a process of mutually convincing one another in which the actions of participants are coordinated on the basis of motivation by reasons." (Habermas, 1984: 392)

But let us return to Davidson. In an attempt to further systematise Davidson's epistemological narrative, we have accentuated several theoretical aspects of his point of view and we would like to particularly emphasise them here. We are of the opinion that it is justifiable to claim that antirepresentational and consensual points can be recognised in Davidson's project which concerns the possibility of knowledge objectivity, and they crave the relief of his epistemological thought. We will say a few short words about each of the aforementioned characterisations.

When we say that Davidson's epistemological position is antirepresentational, we think of the famous characterisation by Rorty in his work Philosophy and Mirror of Nature of the modernist philosophy (epistemology) as being representational. That meant that the modernist philosophy leans against the idea of the human mind as a mirror reflecting the nature, while the success of this mirroring is the basis for having conceptualisations, impressions, ideas, etc., which makes a structural element of every knowledge (Rorty, 1980). We have already emphasised that Davidson's epistemology is set as an antipode to this kind of epistemological construction. Antirepresentationalism of which we here speak is directed towards interpretative evaluation and legitimisation of different practices that are deemed as epistemologically relevant. Every linguistic performance must contain an interpersonal verification in order to be able to be characterised as knowledge. The 
mentioned interpersonal verifiability means a shift towards practical goals that are achieved in communicative situations and it is a plausible alternative to essentialist demands of the traditional epistemology. Participants in communication need to always reflect afresh upon the content, goals and purposes that need to be and are desired to be achieved and that cannot be determined from a reference point that is distant and drawn out of any context. The permanent game of seeking a consensus is what is left in that wondering and seeking for sense, and it is the one thing that we, as linguistically and rationally equipped beings, can hope to achieve as frequently possible, with optimum quality. If we present that through an epistemological concept of subjectivity, then we can state that the subjectivity characterised by communicative reason resists any kind of idea of preserving internal truth and reflects about itself as an integrative part of a larger whole in which it always examines the validity of beliefs and attitudes, both one's own and of others.

\section{Conclusion}

In this paper, we tried to outline the general theoretical postulates of Davidson's epistemological viewpoint. As we have seen, the developmental path Davidson takes in deliberations of knowledge starts with a criticism ofthe traditional division of the conscious content and the outer world, and an analysis of certainty and reliability of the subjective knowledge if that distinction is preserved. Davidson shows that if he manages to prove the unjustifiable favouring of such attitude, then one needs to initiate an epistemological narrative on some other methodological principles. Davidson further shows that the knowledge of self, of the other, of the world around us needs to be understood as a section of a unified corpus of attitudes and beliefs, and that there does not exist an essential difference between them. That initiates identification of intersubjectivity as the only form in which it is reasonable to ask of the knowledge as of something that can be objectively accepted and what is more than just something relative and contingent. In other words, only the intersubjective practice is something that enables the understanding of the notion of knowledge and ways of its application. This viewpoint is always open to alternative conceptions and explanatory vocabularies since it is not limited by transcendent principles in accordance to which linguistic and discursive practices need to be modelled. 


\section{References}

Bilgrami, A. (1999). "Why Is Self-Knowledge Different from Other Kinds of Knowledge", In Hahn, L.E. (ed.) The Philosophy of Donald Davidson, Chicago, La Salle: Open Court Publishing, pp. 211-224.

Davidson, D. (1980). Essays on Actions and Events. Oxford: Oxford University Press.

Davidson, D. (2001a). Subjective, Intersubjective, Objective. Oxford: Clarendon Press.

Davidson, D. (2001b). Inquiries into Truth and Interpretation (2nd edition). Oxford: Oxford University Press.

Davidson, D. (2004). Problems of Rationality. New York: Oxford University Press.

Evnine, Simon (1991). Donald Davidson. Stanford: Stanford University Press.

Habermas, J. (1984). The Theory of Communicative Action, Volume I: Reason and the Rationalisation of Society. Cambridge: Polity Press.

Lepore, E.; Kirk, L. (eds.) (2005). Donald Davidson: Meaning, Truth, Language, and Reality. Oxford: Clarendon Press.

Nagel, Th. (1999). "Davidson's New Cogito", In Hahn, L.E. (ed.), The Philosophy of Donald Davidson. Chicago, La Salle: Open Court Publishing, pp. 195-206.

Rorty, R. (1980). Philosophy and the Mirror of Nature, Princeton: Princeton University Press. Sosa, E. (2003). "Knowledge of Self, Others, and World", in: Kirk Ludwig (ed.), Donald Davidson. Cambridge: Cambridge University Press.

Stroud, B. (1999). "Radical Interpretation and Philosophical Scepticism", In Hahn, L.E. (ed.), The Philosophy of Donald Davidson, Chicago, La Salle: Open Court Publishing, pp. 139-161. 